\title{
Simultaneous Occurrence of Aflatoxins and Fumonisins in Corn Intended for the Pet Feed Industry and for Human Consumption
}

\author{
C. A. F. Oliveira, J. V. S. Cruz, R. E. Rosim, K. Bordin, A. C. P. Kindermann and C. H. Corassin*
}

Department of Food Engineering, College of Animal Science and Food Engineering, University of São Paulo, Av. Duque de Caxias Norte, 225; CEP 13635-900 - Pirassununga, SP, Brazil

"Correspondence to:

Carlos Humberto Corassin, $\mathrm{PhD}$

Department of Food Engineering, College of Animal Science and Food Engineering, University of São Paulo, Av. Duque de Caxias Norte, 225; CEP 13635-900 - Pirassununga SP, Brazil

E-mail: carloscorassin@usp.br

Received: November 09, 2015

Accepted: January 09, 2016

Published: January 11, 2016

Citation: Oliveira CAF, Cruz JVS, Rosim RE, Bordin K, Kindermann ACP, et al. 2016. Simultaneous Occurrence of Aflatoxins and Fumonisins in Corn Intended for the Pet Feed Industry and for Human Consumption. $J$ Food Chem Nanotechnol 2(1): 1-5.

Copyright: ( 2016 Oliveira et al. This is an Open Access article distributed under the terms of the Creative Commons Attribution 4.0 International License (CC-BY) (http://creativecommons. org/licenses/by/4.0/) which permits commercial use, including reproduction, adaptation, and distribution of the article provided the original author and source are credited.

Published by United Scientific Group

\begin{abstract}
In this study, 24 samples of corn intended for the pet feed industry (PFI) and 24 samples of corn for human consumption (HC) commercialized in São Paulo, Brazil were analyzed for aflatoxins $B_{1}, B_{2}, G_{1}$ and $G_{2}$, and fumonisins $B_{1}$ and $B_{2}$ by high performance liquid chromatography. The concentrations of total aflatoxins in positive samples of PFI (33.3\%) and $\mathrm{HC}(70.8 \%)$ corn samples ranged from 0.5 to $3.9 \mu \mathrm{g} / \mathrm{kg}$ and 0.5 to $41.8 \mu \mathrm{g} / \mathrm{kg}$, respectively. For fumonisins, the concentrations in positive samples of PFI (100\%) and HC (83.3\%) corn samples ranged from 685 to $11,379 \mu \mathrm{g} / \mathrm{kg}$ and 157 to $6,495 \mu \mathrm{g} / \mathrm{kg}$, respectively. Overall the aflatoxin levels complied with regulations for food products in Brazil $(20 \mu \mathrm{g} / \mathrm{kg})$, except for one sample of $\mathrm{HC}$ corn. However, the high incidence of fumonisins indicates the need for better agricultural practices to avoid contamination of corn, especially in the PFI.
\end{abstract}

\section{Keywords}

Mycotoxins, Aflatoxin $\mathrm{B}_{1}$, Fumonisin $\mathrm{B}_{1}$, Corn kernels, Occurrence, Quantitative

\section{Introduction}

Mycotoxins are secondary metabolites produced by fungi that grow in food products worldwide, leading to a great variety of toxic effects in vertebrates, including humans [1]. Toxigenic fungi may contaminate food products at different phases of production and processing, mainly under favourable humidity and temperature conditions [2]. In Brazil, the most common toxigenic fungi found in cereals include species from the genera Aspergillus and Fusarium. Aspergillus species, mainly $A$. flavus, $A$. parasiticus and $A$. nomius, produce aflatoxins, which have high toxicity, teratogenicity, mutagenicity and carcinogenicity [3].

There are four major aflatoxins, namely B1, B2, G1 and G2, which can contaminate feed and foodstuffs. However, aflatoxin B1 (AFB1) is the most commonly occurring and has the higher toxigenic potential, with the liver as the main affected organ [2]. The occurrence of AFB1 in food products is a public health concern because the International Agency for Research on Cancer (2015) [4] classified AFB1 in Group 1 - human carcinogen. AFB1 can produce liver tumors in Fisher rats at levels as low as $50 \mu \mathrm{g} / \mathrm{kg}$ [5]. Fumonisins are a group of structurally related mycotoxins produced mainly by Fusarium verticillioides. Although 28 fumonisin analogs have been identified since 1988, fumonisin B1 (FB1) is the most prevalent and also the most toxic, FB1 is considered a possible carcinogen in humans (group 2B) by the International Agency for Research on Cancer (2015) [4]. Since their identification, fumonisins have been associated with animal diseases such as equine leukoencephalomalacia and porcine pulmonary 
edema, although at concentrations nearly 1,000 higher than the toxic levels of AFB1 [3].

Outbreaks related to pet food contaminated with aflatoxins have been described in several countries, including USA [6] and Israel [7], with corn as the usual source of aflatoxins in the feed. Although outbreaks caused by mycotoxins in pet animals have not been described in Brazil, a few cases of natural aflatoxicosis in dogs were reported in Rio Grande do Sul [8]. Moreover, previous studies reported aflatoxin contamination in the $12 \%$ of 4 of samples collected in Santa Catarina State presenting at least one type of mycotoxin [9]. Fumonisinrelated outbreaks in pet animals have not been described in the literature.

Brazilian corn production is around 75 million tons per year, of which approximately $65 \%$ is destined for the animal feeding industry. Previous reports have indicated that the incidence of aflatoxins in Brazilian corn is highly variable, with mean levels of up to $460 \mu \mathrm{g} / \mathrm{kg}[10,11]$. For fumonisins, higher incidences (up to 100\%) were reported in corn, with mean levels ranging from $20-22,600 \mu \mathrm{g} / \mathrm{kg}$ [10-12]. However, there is very little information on the simultaneous occurrence of aflatoxins and fumonisins in Brazilian corn kernels. The objective of the present trial was to evaluate the simultaneous occurrence of fumonisins and aflatoxins in corn kernels available for the pet feed industry (PFI) and for human consumption (HC) in São Paulo, Brazil.

\section{Materials and Methods}

\section{Sampling procedures}

Corn intended for the PFI was collected during the same 6-month period, from a large scale supplier of corn located in Porto Ferreira city, state of São Paulo (4 samples from different batches per month), totaling 24 samples. The supplier received corn from several producers in the state of São Paulo by the time of sampling, stored the product for a period of time and distributed it for at least 8 pet feed factories in the state. Sampling procedures followed the recommendations of Food and Agriculture Organization [13]. Incremental portions of corn were collected at different intervals during the transference of kernels from trucks to the storage silos, until reaching $16 \mathrm{~kg}$ of corn for each sample. The kernels were collected in sterile polypropylene bags, identified and kept at room temperature until analysis.

Samples of packaged corn kernels for $\mathrm{HC}$ were collected in the cities of Araras, Leme, Pirassununga and Porto Ferreira, all located in the Northeast of the state of São Paulo. In each city, samples from the brands that showed the greatest trade volume in supermarkets were collected from January to June 2008 (4 samples per month, one per city), totalling 24 samples of corn. The sampling unit was made up of original closed packages of at least $500 \mathrm{~g}$ of kernels, collected from different batches as indicated in the label, avoiding batch repetition. Samples were identified, including data on the manufacturer, batch and/or manufacturing date and expiring date. Products were stored in their respective packages and kept at room temperature (same supermarket conditions) until the moment of analysis.

\section{Extraction of aflatoxins and fumonisins}

The extraction and purification of aflatoxins $\left(B_{1}, B_{2}, G_{1}\right.$ and $G_{2}$ ) and fumonisins $\left(B_{1}\right.$ and $B_{2}$ ) in PFI and $\mathrm{HC}$ samples were performed using immunoaffinity columns, following manufacturer recommendations (Aflatest ${ }^{\circledR}$ or Fumonitest ${ }^{\circledR}$, Vicam, Watertown, MA, USA). Previously, the total amount of corn samples collected in supermarkets and a $2.5 \mathrm{~kg}$ subsample of corn collected in the supplier were grinded in a hammer mill (Marconi, Piracicaba, Brazil) until a particle size of nearly 14 mesh, and mixed thoroughly. An aliquot of each sample $(50 \mathrm{~g}$ ) was weighted in an Erlenmeyer flask containing $5 \mathrm{~g}$ of sodium chloride and $100 \mathrm{ml}$ of methanol/water $(80: 20, \mathrm{v} / \mathrm{v})$ were added. The flask was placed in an orbital shaker (Tecnal, Piracicaba, Brazil) for 30 minutes, the flask content was filtered and $10 \mathrm{ml}$ of the filtrate were placed in a Becker. $40 \mathrm{ml}$ of ultra-pure water (Milli Q, Millipore, Bedford, MA, USA) were added and the mixture was filtered in a $1.5 \mu \mathrm{m}$ microfiber filter. Two $10 \mathrm{ml}$ aliquots were then passed through the immunoaffinity columns (Aflatest ${ }^{\circledR}$ or Fumonitest ${ }^{\circledR}$ ) at flow rate of 1-2 drops/sec. After washing with $10 \mathrm{ml}$ of ultrapure water, aflatoxins or fumonisins were eluted from their respective columns with $1 \mathrm{ml}$ of methanol, being each eluate collected in an amber vial. The aflatoxins and fumonisins eluates were evaporated to dryness under nitrogen flow.

\section{Determination of aflatoxins}

$\mathrm{AFB}_{1}$ and $\mathrm{AFG}_{1}$ in the final extracts were derivatized by adding $200 \mu \mathrm{L}$ of $\mathrm{n}$-hexane and $200 \mu \mathrm{L}$ of trifluoroacetic acid (TFA) to the aflatoxin dried extract [14]. The mixture was kept at $40{ }^{\circ} \mathrm{C}$ for $10 \mathrm{~min}$, evaporated to near-dryness and diluted in $1 \mathrm{ml}$ of methanol: water (50:50, v/v). Final extracts were filtered through a $0.45 \mu \mathrm{m}$ PTFE membrane and $20 \mu \mathrm{L}$ were injected into a Shimadzu (Kyoto, Japan) 10VP high performance liquid chromatograph (HPLC) with a 10 AXL fluorescence detector (excitation at $360 \mathrm{~nm}$ and emission above $440 \mathrm{~nm}$ ). A Shim-Pack CLC-ODS Sil column (4.6 X $250 \mathrm{~mm}, 5 \mu \mathrm{m})$ and a Shim-Pack pre-column (4 X $10 \mathrm{~mm}$, $5 \mu \mathrm{m}$ CLC G-ODS) were used. The isocratic mobile phase consisted of methanol-water $(45: 55, \mathrm{v} / \mathrm{v})$ with a flow rate of $1.0 \mathrm{ml} / \mathrm{min}$. Calibration curves were prepared using standard solutions of aflatoxins $\mathrm{B}_{1}, \mathrm{~B}_{2}, \mathrm{G}_{1}$ and $\mathrm{G}_{2}$ (Sigma, St Louis, $\mathrm{MO}$, USA) previously evaluated according to Scott (1990) [14]. The individual aflatoxins solutions were mixed in convenient volumes to reach working solutions at the concentrations of 2.5, 5.0, 10.0 and $20.0 \mathrm{ng} / \mathrm{ml}$ of each aflatoxin. Aflatoxins working solutions were prepared with TFA similarly to the sample extracts. The retention times were approximately 4.2 min for $\mathrm{AFG}_{1}$ (converted to $\mathrm{AFG}_{2 \mathrm{a}}$ ), $5.0 \mathrm{~min}$ for $\mathrm{AFB}_{1}$ (converted to $\mathrm{AFB}_{2 \mathrm{a}}$ ), $7.1 \mathrm{~min}$ for $\mathrm{AFG}_{2}$ and $9.7 \mathrm{~min}$ for $\mathrm{AFB}_{2}$ (Figure 1).

\section{Determination of fumonisins}

Fumonisin dried extracts were re-diluted with $200 \mu \mathrm{L}$ of acetonitrile-water (50:50, v/v) and filtered using a $0.45 \mu \mathrm{m}$ PTFE membrane. A $100-\mu \mathrm{L}$ aliquot was placed in a test tube. After that, $200 \mu \mathrm{L}$ of 0 -phthaldialdehyde (OPA) reagent (prepared using $40 \mu \mathrm{g}$ of OPA diluted in $5 \mathrm{~mL}$ of sodium tetraborate solution $0.1 \mathrm{M}$ and $50 \mu \mathrm{L}$ of 2-mercaptoethanol) were added. After 2 minutes, $20 \mu \mathrm{L}$ were used for quantification of the toxins in the same HPLC system described before, with a 


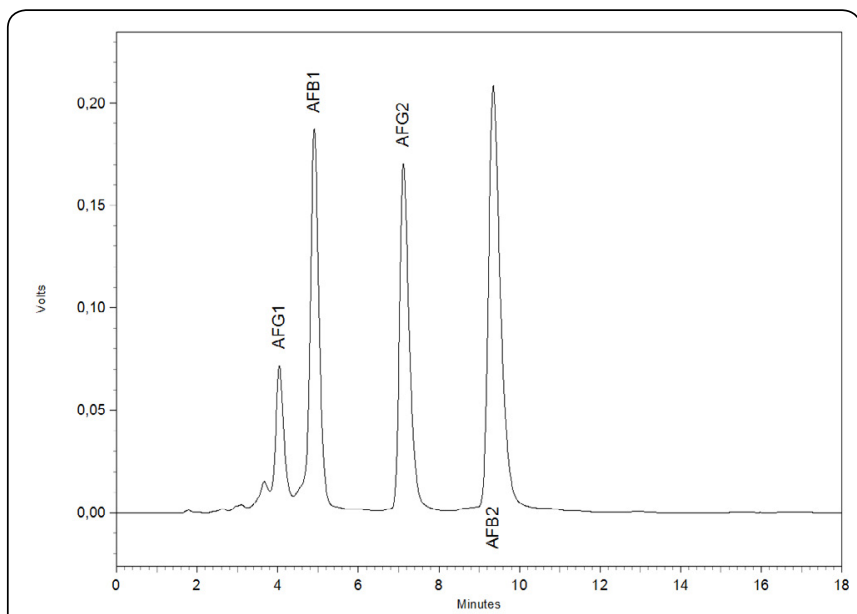

Figure 1: Chromatogram showing the retention times of aflatoxin standards ( $20.0 \mathrm{ng} / \mathrm{ml}$ of each compound): AFG1 (converted to AFG2a) (nearly $4.2 \mathrm{~min}$ ), AFB1 (converted to AFB2a) (nearly $5.0 \mathrm{~min}$. .), AFG2 (nearly $7.1 \mathrm{~min}$.) and AFB2 (nearly 9.7 min.).

reverse phase $\mathrm{C}_{18}$ column $(150 \times 4.6 \mathrm{~mm}$, particle size $5 \mu \mathrm{m}$ - Phenomenex, Torrance, USA) kept at constant temperature of $30{ }^{\circ} \mathrm{C}$. Mobile phase was made up of acetonitrile-wateracetic acid (50:50:1, v/v), and constant flow of $1.0 \mathrm{ml} / \mathrm{min}$ was used. Detection of derivatized fumonisins was performed using the same HPLC system as described for aflatoxins, under fluorescence from 335 to $440 \mathrm{~nm}$ for excitation and emission, respectively. The calibration curves were performed from successive chromatographic measurements of $\mathrm{FB}_{1}$ and $\mathrm{FB}_{2}$ standards in triplicate at concentrations of $0.313,0.625$, $1.25,2.5$ and $5.0 \mu \mathrm{g} / \mathrm{ml}$ of each fumonisin. Retention time was approximately 9.5 minutes for $\mathrm{FB}_{1}$ and 27.4 minutes for $\mathrm{FB}_{2}$ (Figure 2).

\section{Validation procedures}

The limits of detection (LOD) and quantification (LOQ) were calculated for each method of analysis based on signal:noise ratio of 3:1 and 10:1, respectively. Linearity was evaluated by verifying the coefficient of determination $\left(\mathrm{r}^{2}\right)$ and

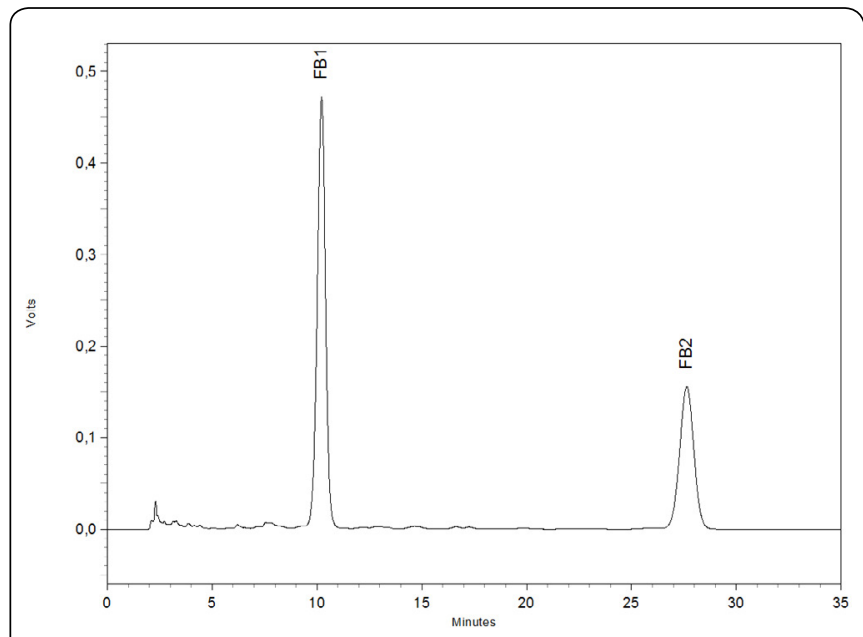

Figure 2: Chromatogram showing the retention times of fumonisin standards $(5.0 \mu \mathrm{g} / \mathrm{ml}$ of each compound): FB1 (nearly $9.5 \mathrm{~min}), \mathrm{FB} 2$ (nearly $27.4 \mathrm{~min}$.).

visual inspection of residual plots of analytical curves built separately for each mycotoxin. The analytical methods used in the experiment were evaluated using commercially available corn samples previously analyzed for endogenous $\mathrm{AFB}_{1}$ and
$\mathrm{FB}_{1}$. Triplicate samples were spiked with $\mathrm{AFB}_{1}$ and $\mathrm{FB}_{1}$ at levels of 2 and $20 \mu \mathrm{g} / \mathrm{kg}$ and 50 and $500 \mu \mathrm{g} / \mathrm{kg}$, respectively. All these fortified samples were analyzed as described for samples collected in supermarkets and in the corn supplier.

\section{Results and Discussions}

\section{Method performance}

Recovery values [Table 1] for aflatoxins and fumonisins ranged from 77.5 to $103.7 \%$ and 78.2 to $93.4 \%$, respectively. Relative standard deviations were lower than $13.2 \%$ for aflatoxins, and $15.7 \%$ for fumonisins, which comply with the requirements of the EC directive 401/2006 [15]. LOD and LOQvalues for $\mathrm{AFB}_{1}, \mathrm{AFB}_{2}, \mathrm{AFG}_{1}$ and $\mathrm{AFG}_{2}$ were 0.15 and $0.5 \mu \mathrm{g} / \mathrm{kg}$, respectively. For $\mathrm{FB}_{1}$ and $\mathrm{FB}_{2}, \mathrm{LOD}$ and LOQwere 10 and $30 \mu \mathrm{g} / \mathrm{kg}$, respectively.

\section{Aflatoxins and fumonisins in corn samples}

Aflatoxins and fumonisins levels in PFI and $\mathrm{HC}$ corn samples are shown in [Table 2]. Corn intended for $\mathrm{HC}$ presented high incidence $(70.8 \%)$ of total aflatoxins $\left(\mathrm{B}_{1}+\mathrm{B}_{2}\right.$ $+\mathrm{G}_{1}+\mathrm{G}_{2}$ ) at levels ranging from 0.5 to $41.8 \mu \mathrm{g} / \mathrm{kg}$ (mean:

\footnotetext{
Table 1: Performance of the analytical methods for aflatoxins and fumonisins in corn intended for human consumption and for the pet feed industry in São Paulo, Brazil.
}

\begin{tabular}{|l|c|c|c|}
\hline Mycotoxin & $\begin{array}{c}\text { Spiking level } \\
(\boldsymbol{\mu g} / \mathbf{k g})\end{array}$ & Recovery (\%)1 & $\begin{array}{c}\text { Relative standard } \\
\text { deviation (\%) }\end{array}$ \\
\hline $\mathrm{AFB}_{1}$ & 2.0 & $88.0 \pm 7.7$ & 12.3 \\
\hline $\mathrm{AFB}_{1}$ & 20.0 & $103.7 \pm 2.9$ & 3.1 \\
\hline $\mathrm{AFB}_{2}$ & 2.0 & $90.3 \pm 8.1$ & 9.7 \\
\hline $\mathrm{AFB}_{2}$ & 20.0 & $99.5 \pm 4.5$ & 5.3 \\
\hline $\mathrm{AFG}_{1}$ & 2.0 & $84.2 \pm 8.9$ & 10.1 \\
\hline $\mathrm{AFG}_{1}$ & 20.0 & $100.3 \pm 4.3$ & 4.7 \\
\hline $\mathrm{AFG}_{2}$ & 2.0 & $92.4 \pm 11.2$ & 13.2 \\
\hline $\mathrm{AFG}_{2}$ & 20.0 & $77.5 \pm 4.7$ & 6.5 \\
\hline $\mathrm{FB}_{1}$ & 50 & $78.2 \pm 8.0$ & 10.4 \\
\hline $\mathrm{FB}_{1}$ & 500 & $93.4 \pm 6.5$ & 6.9 \\
\hline $\mathrm{FB}_{2}$ & 50 & $89.8 \pm 12.2$ & 15.7 \\
\hline $\mathrm{FB}_{2}$ & 500 & $83.4 \pm 7.1$ & 8.3 \\
\hline
\end{tabular}

${ }^{1}$ Values expressed as mean \pm standard deviation of samples analyzed in triplicate.

$4.4 \pm 9.8 \mu \mathrm{g} / \mathrm{kg})$. Although a limited number of samples was analyzed $(n=24)$, one sample $(4.1 \%)$ had total aflatoxins above the permitted maximum limit $(20 \mu \mathrm{g} / \mathrm{kg})$ adopted by Brazilian regulations [16], hence indicating health risks associated to dietary exposure to aflatoxins in Brazil. Another sample had $6.7 \mu \mathrm{g} / \mathrm{kg} \mathrm{AFB}_{1}$, which is higher than the limit adopted by the European Union $\left(5 \mu \mathrm{g} / \mathrm{kg}\right.$ for $\mathrm{AFB}_{1}$ and $10 \mu \mathrm{g} / \mathrm{kg}$ for total aflatoxins) [17]. For fumonisins, the percentage of positive samples was even higher (83.3\%), with levels ranging from 157 to $6,495 \mu \mathrm{g} / \mathrm{kg}$ (mean: $2,597 \pm 1,958 \mu \mathrm{g} / \mathrm{kg}$ ). 10 samples $(41.7 \%)$ had concentrations above the limit for $\mathrm{FB}_{1}$ and $\mathrm{B}_{2}$ $(2,000 \mu \mathrm{g} / \mathrm{kg})[16]$.

Despite the limitations in the sample collection, results for aflatoxins alone in $\mathrm{HC}$ corn in this trial were higher 
than previous data reported in Brazil. Bento et al., [18] found aflatoxins in $19 \%$ and $23.8 \%$ of corn samples from Mato Grosso state harvested in 2009 and 2010 respectively,

Table 2: Aflatoxins and fumonisins in corn intended for human consumption and for the pet feed industry in São Paulo, Brazil.

\begin{tabular}{|c|c|c|c|c|}
\hline Mycotoxin & $\boldsymbol{n}^{\mathbf{1}}$ & $\mathbf{\%}^{\mathbf{2}}$ & $\begin{array}{c}\mathbf{R a n g e}^{\mathbf{3}} \mathbf{( \mu g} / \\
\mathbf{~ g g})\end{array}$ & $\mathbf{M e a n}^{\mathbf{4}}(\boldsymbol{\mu g} / \mathbf{k g})$ \\
\hline $\begin{array}{l}\text { Corn for human } \\
\text { consumption: }\end{array}$ & & & & \\
\hline Aflatoxin $\mathrm{B}_{1}$ & 17 & 70.8 & $0.5-38.0$ & $3.5 \pm 9.0$ \\
\hline Aflatoxin $\mathrm{B}_{2}$ & 2 & 8.3 & $0.5-0.6$ & $0.6 \pm 0.1$ \\
\hline Aflatoxin $\mathrm{G}_{1}$ & 5 & 20.8 & $0.5-4.5$ & $2.3 \pm 1.5$ \\
\hline Aflatoxin $\mathrm{G}_{2}$ & 2 & 8.3 & $0.5-0.7$ & $0.6 \pm 0.1$ \\
\hline Total aflatoxins & 17 & 70.8 & $0.5-41.8$ & $4.4 \pm 9.8$ \\
\hline Fumonisin $\mathrm{B}_{1}$ & 20 & 83.3 & $157-6,204$ & $2,537 \pm 1,949$ \\
\hline Fumonisin $\mathrm{B}_{2}$ & 12 & 50.0 & $30-291$ & $100 \pm 91$ \\
\hline Total fumonisins & 20 & 83.3 & $157-6,495$ & $2,597 \pm 1,958$ \\
\hline & & & & \\
\hline $\begin{array}{l}\text { Corn for pet feed } \\
\text { industry: }\end{array}$ & & & & \\
\hline Aflatoxin $\mathrm{B}_{1}$ & 8 & 33.3 & $0.5-1.6$ & $0.8 \pm 0.4$ \\
\hline Aflatoxin $\mathrm{B}_{2}$ & 0 & 0 & - & - \\
\hline Aflatoxin $\mathrm{G}_{1}$ & 4 & 16.7 & $0.5-0.8$ & $0.7 \pm 0.1$ \\
\hline Aflatoxin $\mathrm{G}_{2}$ & 2 & 8.3 & $1.0-2.3$ & $1.7 \pm 0.9$ \\
\hline Total aflatoxins & 8 & 33.3 & $0.5-3.9$ & $1.5 \pm 1.1$ \\
\hline Fumonisin $\mathrm{B}_{1}$ & 24 & 100.0 & $539-9,707$ & $3,275 \pm 2,098$ \\
\hline Fumonisin $\mathrm{B}_{2}$ & 20 & 83.3 & $97-1,979$ & $683 \pm 586$ \\
\hline Total fumonisins & 24 & 100.0 & $685-11,379$ & $3,845 \pm 2,570$ \\
\hline
\end{tabular}

${ }^{1}$ Number of samples above the limit of quantification (LOQ) of the analytical methods $\left(0.5 \mu \mathrm{g} / \mathrm{kg}\right.$ for aflatoxins $\mathrm{B}_{1}, \mathrm{~B}_{2}, \mathrm{G}_{1}$ and $\mathrm{G}_{2}$, and $30 \mathrm{mg} /$ $\mathrm{kg}$ for fumonisins $\mathrm{B}_{1}$ and $\mathrm{B}_{2}$ ).

${ }^{2}$ Percentage of positive samples of the total analysed samples of corn for pet feed industry $(\mathrm{n}=24)$ and for human consumption $(\mathrm{n}=24)$ ".

${ }^{3}$ Minimum and maximum levels quantified in analysed samples in duplicate.

${ }^{4}$ Values are reported as means $\pm \mathrm{SD}$, for samples containing quantifiable levels of each mycotoxin.

although at higher levels $(1.0$ to $108.7 \mu \mathrm{g} / \mathrm{kg}$ ). $8 \%$ of 300 samples of freshly harvested corn collected in the reception and pre-drying steps in Paraná State had aflatoxins at mean concentration of $30.6 \mu \mathrm{g} / \mathrm{kg}$ [11]. However, the authors found fumonisins in $100 \%$ of the analyzed samples, with similar mean levels $(2,082 \mu \mathrm{g} / \mathrm{kg})$ as obtained in the present study. Moreover, the mean fumonisin level in corn intended for $\mathrm{HC}$ as presented in our work were in agreement with those found by Westhuizen et al. [12], in Santa Catarina state (mean: 2,870 $\mu \mathrm{g} / \mathrm{kg}$ ). In summary, the low levels of aflatoxin and high levels and incidence of fumonisin in corn reported in the present study is in accordance with previous studies indicating that producers of corn for HC have improved control practices to avoid contamination of corn grain with aflatoxin, but not fumonisin.

Samples of corn intended for PFI also presented low levels of aflatoxins, ranging from 0.5 to $3.9 \mu \mathrm{g} / \mathrm{kg}$ with a mean of total aflatoxins of $1.5 \mu \mathrm{g} / \mathrm{kg}$ [Table 2]. No sample had levels higher than the recommended level of aflatoxins for feed ingredients marketed in Brazil $(50 \mu \mathrm{g} / \mathrm{kg})$ [19]. However, fumonisins were detected in all samples analyzed, at levels ranging from 685 to $11,379 \mu \mathrm{g} / \mathrm{kg}$ (mean: $3,845 \pm 2,570 \mu \mathrm{g} / \mathrm{kg}$ ), which is higher than fumonisin levels found in samples of corn intended for HC. Importantly, there is no regulation for fumonisins in feedstuffs in Brazil, and the recommended level for aflatoxins $(50 \mu \mathrm{g} / \mathrm{kg})$ is not an action level.

The comparison with our results with previous data is difficult because there is no report on the occurrence of aflatoxins or fumonisins in corn intended for the pet industry in Brazil. However, aflatoxin-contaminated pet feeds have been found in surveys conducted in the states of Minas Gerais [20] and Santa Catarina [9]. Pleadin et al. [21] confirmed the corn as the main source of aflatoxin contamination in feeds in Croatia, where high incidences of aflatoxins at levels ranging from 1.1 to $2,072 \mu \mathrm{g} / \mathrm{kg}$ were found in corn samples from different farms and feed factories. $\mathrm{FB}_{1}$ levels in PFI or $\mathrm{HC}$ samples obtained in the presented study were higher when compared with those reported by Mngadi et al. [22], who

Table 3: Simultaneous occurrence of aflatoxins and fumonisins in corn intended for human consumption and for the pet feed industry in São Paulo, Brazil.

\begin{tabular}{|c|c|c|}
\hline Sample number & $\begin{array}{l}\text { Total aflatoxins }{ }^{1} \\
\quad(\mu \mathrm{g} / \mathrm{kg})\end{array}$ & $\begin{array}{c}\text { Total fumonisins } \\
(\mu \mathrm{g} / \mathrm{kg})\end{array}$ \\
\hline \multicolumn{3}{|l|}{$\begin{array}{l}\text { Corn for human } \\
\text { consumption: }\end{array}$} \\
\hline 1 & 4.0 & 431 \\
\hline 2 & 0.9 & 1,396 \\
\hline 3 & 0.7 & 1,376 \\
\hline 4 & 0.8 & 4,685 \\
\hline 5 & 0.7 & 5,276 \\
\hline 6 & 0.9 & 3,092 \\
\hline 7 & 1.7 & 6,495 \\
\hline 8 & 1.0 & 4,279 \\
\hline 9 & 4.6 & 4,022 \\
\hline 10 & 2.6 & 4,183 \\
\hline 11 & 41.8 & 467 \\
\hline 12 & 7.3 & 488 \\
\hline 13 & 0.6 & 404 \\
\hline Mean \pm SD & $5.2 \pm 11.2$ & $2,815 \pm 2,144$ \\
\hline \multicolumn{3}{|c|}{ Corn for pet feed industry: } \\
\hline 14 & 1.7 & 11,379 \\
\hline 15 & 1.2 & 8,284 \\
\hline 16 & 3.9 & 6,541 \\
\hline 17 & 0.5 & 6,162 \\
\hline 18 & 0.8 & 2,193 \\
\hline 19 & 1.0 & 2,657 \\
\hline 20 & 1.8 & 4,053 \\
\hline 21 & 1.3 & 2,420 \\
\hline Mean \pm SD & $1.5 \pm 1.1$ & $5,461 \pm 3,261$ \\
\hline
\end{tabular}

${ }^{1}$ Sum of aflatoxins $B_{1}, B_{2}, G_{1}$ and $G_{2}$. ${ }^{2}$ Sum of fumonisins $\mathrm{B}_{1}$ and $\mathrm{B}_{2}$. 
found concentrations of 15 to $5,900 \mu \mathrm{g} / \mathrm{kg}$ in 23 animal feed from South Africa. The results also showed a contamination by fumonisins in $100 \%$ of corn samples evaluated. On the other hand, in Santa Catarina State, Scussel et al. [9], detected fumonisin in $11 \%$ of the 123 pet feed samples.

Despite the high incidence and levels of fumonisins in Brazil, there is no legally maximum limit for these mycotoxins in animal feed. The tolerance limit for FBs adopted by the European Union is $60,000 \mu \mathrm{g} / \mathrm{kg}$ for corn and corn products and $5,000 \mu \mathrm{g} / \mathrm{kg}$ for complementary and complete feedingstuff for pet animals [23]. In our study, no corn sample had fumonisins levels above this limit. However, one sample had $11,379 \mu \mathrm{g} / \mathrm{kg}$, which is above the U.S. Food and Drug Administration recommendation for total fumonisins $(10,000 \mu \mathrm{g} / \mathrm{kg})$ in corn [24].

The simultaneous occurrence of aflatoxins and fumonisins was found in $54.2 \%$ samples of corn intended for $\mathrm{HC}$, and in $33.3 \%$ samples of corn for the PFI, as presented in [Table 3]. The levels of fumonisins were higher in corn destined for feed pet industry, hence indicating that better control practices are applied to corn kernels destined for $\mathrm{HC}$, reflecting specially with agronomic practices and climatic conditions. The higher fumonisin contamination in corn for animal consumption can also be due to a greater period that corn is stored before being used in industry, in addition to worst conditions of storage.

\section{Conclusion}

The simultaneous occurrence of aflatoxins and fumonisins in corn reinforces the need for regulations for mycotoxins in feedstuffs in Brazil, to avoid potential health risks in feed supply industry.

Samples of corn intended for the PFI, and corn kernels commercially available for $\mathrm{HC}$ in the Northeast region of São Paulo State presented high incidences of aflatoxins and fumonisins. Although the mean concentrations of aflatoxins in corn samples were below the maximum limit established adopted in Brazil, high fumonisin levels were found in all samples, especially in corn intended for the PFI. There is a need for regulations for mycotoxins in feedstuffs in Brazil.

\section{References}

1. Bryden WL. 2012. Mycotoxin contamination of the feed supply chain: Implications for animal productivity and feed security. Anim Feed Sci Tech 173(s1-2): 134-158. doi: 10.1016/j.anifeedsci.2011.12.014

2. Oliveira CAF, Corrêa B. 2010. Interactive effects between mycotoxins in livestocks. In: Goncalez E, Felicio JA, Aquino S (eds) Mycotoxicoses in animals economically important pp. 117-129.

3. Oliveira CAF, Corassin CH, Corrêa B, Oswald IP. 2014. Animal health: Mycotoxins. In: Neal Van Alfen. (Org.). Encyclopedia of Agriculture and Food Systems 1: 358-377.

4. International Agency for Research on Cancer. 2015. Agents classified by the IARC monographs 1-111.

5. Cullen JM, Ruebner BH, Hsieh LS, Hyde DM, Hsieh DP. 1987. Carcinogenicity of dietary aflatoxin $\mathrm{M}_{1}$ in male Fisher rats compared to aflatoxin $B_{1}$. Canc Res 47(7): 1913-1917

6. Food and Drug Administration. 2005. FDA Issues consumer alert on contaminated pet food. Washington, DC, USA: FDA
7. Bruchim YG, Segev U, Sela T, Bdolah-Abram A, Aroch I, et al. 2012. Accidental fatal aflatoxicosis due to contaminated commercial diet in 50 dogs. Res Vet Sci 93(1): 279-287. doi: 10.1016/j.rvsc.2011.07.024

8. Gomes AR, Pereira CM, Sallis ESV, Pereira DIB, Schild AL, et al. 2014. Aflatoxicosis in dogs in Southern Rio Grande do Sul. Pesq Vet Bras 34(2): 162-166. doi: 10.1590/S0100-736X2014000200011

9. Scussel VM, Giordano BNE, Simão V, Rocha MW, Reis LFC, et al. 2006. Mycotoxin evaluation in feed for pets using tandem liquid chromatography mass/mass. In Proceedings of the 9th International Working Conference on Storage Product Protection, Campinas, SP, Brazil.

10. Ono EY, Ono MA, Funo FY, Medina AE, Oliveira TC, et al. 2001. Evaluation of fumonisin-aflatoxin co-occurrence in Brazilian corn hybrids by ELISA. Food Addit Contam 18(8): 719-729. doi: $10.1080 / 02652030118906$

11. Moreno EC, Garcia GT, Ono MA, Vizoni E, Kawamura O, et al. 2009. Co-occurrence of mycotoxins in corn samples from the Northern region of Paraná State, Brazil. Food Chem 116(1): 220-226. doi: 10.1016/j. foodchem.2009.02.037

12. Westhuizen, L, Shepard GS, Scussel VM, Costa LLF, Vismer HF, et al. 2003. Fumonisin contamination and fusarium incidence in corn from Santa Catarina, Brazil. J Agri Food Chem 51(18): 5574-5578. doi: 10.1021/jf034298z

13. Whitaker TB, Slate AB, Doko MB, Maestroni BM, Cannavan A. 2010. Sampling procedures to detect mycotoxins in agricultural commodities.

14. Scott PM. 1990. Natural poisons. In: Helrich K (eds) Official Methods of Analysis of the Association of Official Analytical Chemists, pp. 1184-1213.

15. European Commission. 2006. Commission Regulation (EC) No 401/2006 of 23 February 2006 laying down the methods of sampling and analysis for the official control of the levels of mycotoxins in foodstuffs. Official Journal of the European Union, L70.

16. Brasil. 2011. Agência Nacional de Vigilância Sanitária. Dispõe sobre limites máximos tolerados (LMT) para micotoxinas em alimentos. Resolução RDC no 7, de 18 de fevereiro de.

17. European Commission. 2010. Commission Regulation (EC) No 165/2010 of 27 February 2010 setting maximum levels for certain contaminants in foodstuffs as regards aflatoxins. Official Journal of the European Union, L50

18. Bento LF, Caneppele MAB, Albuquerque MCF, Kobayasti L, Caneppele C, et al. 2012. Occurrence of fungi and aflatoxins in maize grains. $R$ Inst Adolfo Lutz 71: 44-49.

19. Brazil. 1998. Ministério da Agricultura. Estabelece limites recomendáveis para aflatoxinas em qualquer matéria prima a ser utilizada diretamente ou como ingrediente para rações destinadas ao consumo animal. Portaria MA/SNAD/SFA no 07, de 9 de novembro de 1988

20. Maia PP, Siqueira MEB. 2002. Occurrence of aflatoxins B1, B2, G1 and G2 in some Brazilian pet foods. Food Addit Contam 19(12): 1180-1183. doi: $10.1080 / 0265203021000011214$

21. Pleadin J, Vulic A, Persi N, Skrivanko M, Capek B, et al. 2014. Aflatoxin B1 occurrence in maize sampled from Croatia farms and feed factories during 2013. Food Cont 40: 286-291. doi: 10.1016/j. foodcont.2013.12.022

22. Mngadi PT, Govinden R, Odhav B. 2008. Co-occurring mycotoxins in animal feeds. African J Biotech 7(13): 2239-2243.

23. European Commission. 2006. Commission Recommendation (EC) No 576/2006 of 17 August 2006 on the presence of deoxynivalenol, zearalenone, ochratoxin A, T-2 and HT-2 and fumonisins in products intended for animal feeding. Official Journal of the European Union, L229.

24. Food and Drug Administration. 2001. Guidance for industry: fumonisin levels in human foods and animal feeds. Washington, DC, USA: FDA. 